Dorling, D. and Hennig, B. (2016) London and the English desert - the geography of cultural capital in the UK, Cultural Trends, available first on-line February 4th. DOI:10.1080/09548963.2015.1134097

\title{
London and the English desert - the geography of cultural capital in the UK
}

\author{
Danny Dorling and Benjamin D. Hennig \\ School of Geography and the Environment, University of Oxford, Oxford, UK
}

People in the UK and especially the English have become culturally attuned to seeing and experiencing a geography of extreme inequality as normal. Occasionally, new statistics are produced that show these gross inequalities in a new light and which then cause some shock. This was the case in 2013 when a report on arts funding highlighted just how concentrated such funding was within London, but we should not be so shocked by such a finding. It turns out that what that report really showed was a continuation of a now long established trend in which London gains more and more of the cake, a slight thicker slice each year as compared to the year before.

The idea that capital city could grow in wealth and power to eclipse the country it was based in was muted many decades ago in France with the publication of "Paris et le désert français" (Gavier, 1958). By addressing the issue in France in the 1950s and 1960s, the growing power of Paris was muted. No serious attempt to address the issue in the UK has been made. Government department and quangos responsible for funding cultural development in the UK often deny that the cultural desertification process is now in operation in the UK but numerous empirical analyses " challenge the ACE and DCMS denials that inequity in distribution of their funding has any important impact" (Brook, 2016). Many arts activities still occur outside of the capital, but they do so in the face of financial starvation. In October 2013, the report "Rebalancing our Cultural Capital" (RoCC) was published (Stark, Gordon, \& Powell, 2013). It hit the headlines because of its shocking message on the distribution of arts funding by government, which described how concentrated that funding was in London and how arts funding was becoming more and more concentrated in the Capital over time (see Figure 1). It should have perhaps not have been that shocking because, just like a number of other independent reports, some of which were published over three decades (see e.g. Hutchison,1982), it highlighted that this concentration was mainly a continuation of past concentrations. See Figure 1 caption for another way in which the figures could have been presented. 
Much of the arts is not funded simply by direct taxation, but by the proceeds of the national lottery. In 2014, the authors of the 2013 report estimated that:

The local authority area with the poorest return is County Durham, where its Lottery players have contributed $£ 34$ million since 1995, while it has received $£ 12$ million - a net deficit (in effect a contribution to the surpluses of others) of $£ 22$ million. (http://www.gpsculture.

co.uk/place.php)

The inequality in arts funding appears shocking but it is, in fact, not as shocking as other key inequalities as the rest of this short paper demonstrates.
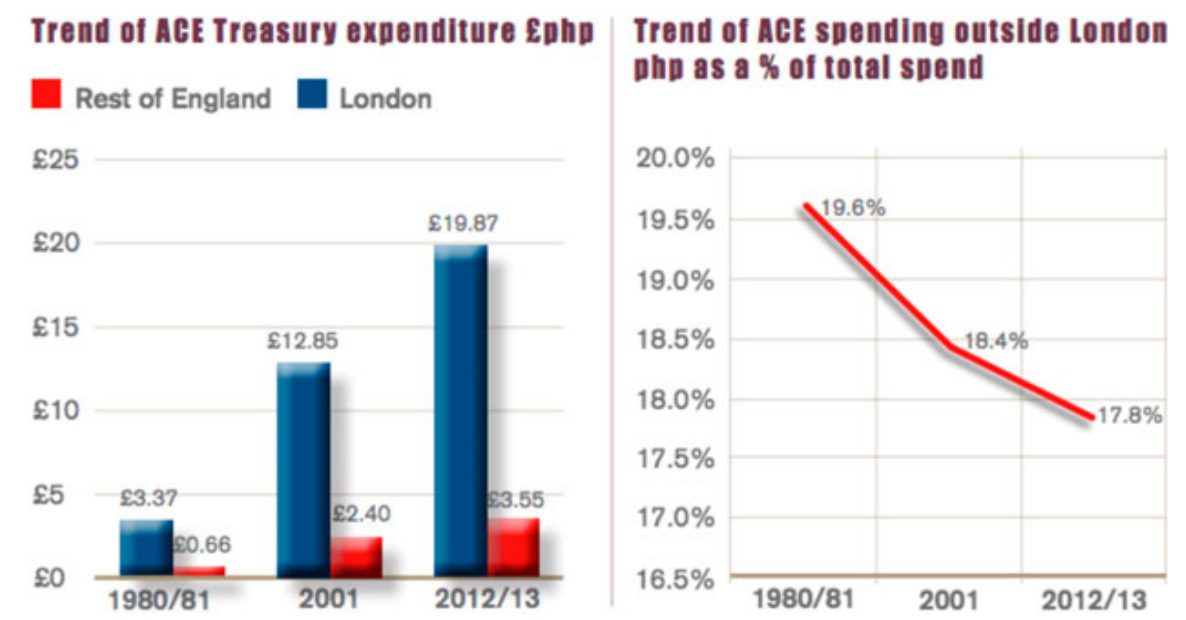

The Department of Culture Media and Sport (DCMS) also funds 16 major 'national' cultural organisations directly. In 2012/13 we estimate that $90 \%$ of the $£ 450 \mathrm{~m}$ available was of direct benefit to London. Combining this direct DCMS expenditure with that of Arts Council England produces a benefit per head of population in the capital of $£ 68.99$ compared to $£ 4.58$ in the rest of England (6.6\% of London levels).

Figure 1. This first figure is a screenshot of the two key graphs in the "RoCC" report (Stark et al., 2013). RoCC is not the first time the report of this kind. Although the rise in spending in London looks very large presented this way the ratios of London versus the rest of England spending are 5.1:1 in 1980/ 1981, rising to 5.4:1 and then 5.6:1 in 2012/2013. Arts spending is still concentrating in London but slightly less quickly than it was, partly because there is so little government arts money not spent outside of London nowadays.

Figure 2 shows that London is, indeed, the greatest sink of England (ACE) funding, but also that the neighbouring South East and East regions, which are just as populous as London, lose out greatly in funding due to their proximity to the capital (Mermeri, 2010). In fact, the totals for the North of England suggest that it does badly, but not terribly badly, compared to the South of England in total.

Compare Figure 2, of ACE funding by region, with the map in Figure 3, which shows the total value of housing sold in each region of England (and London boroughs) in 2014. ACE funding is more evenly distributed than housing value (Phillips, 2012). And clearly, the South West of England fairs especially badly when it comes to ACE funding. But then, perhaps, less is spent on lottery tickets in that area. Of course there 
is no direct connection between buying lottery tickets and grant funding - but people who are poorer tend to buy more lottery tickets and to live in the North of England, Wales and Scotland and a proportion of those ticket sales are used for Arts funding.
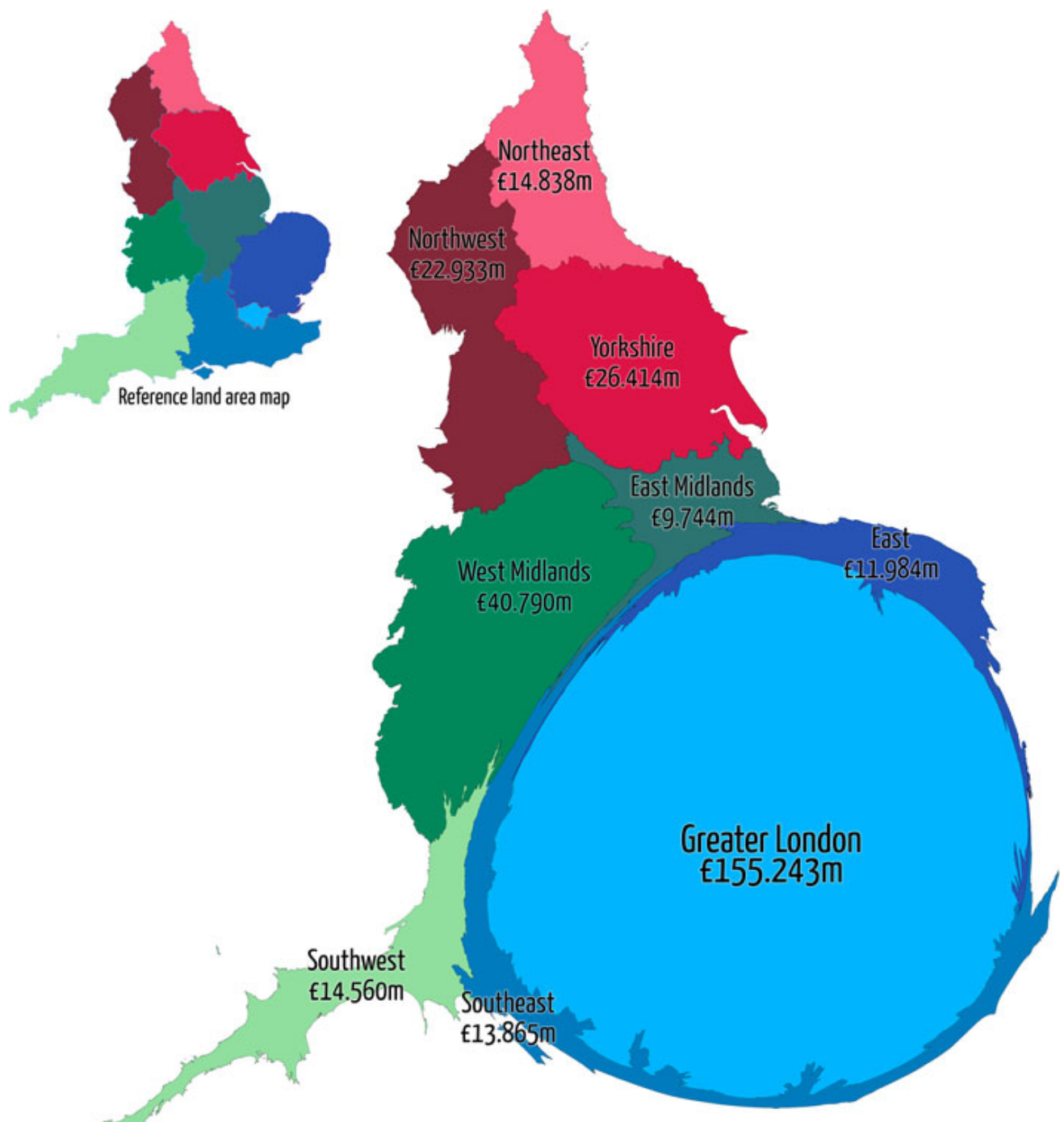

Cartogram resizing the regions according to the total distribution of funding

Figure 2. Here each region is shown with its size drawn in proportion to its share of Arts Council Funding. Maps of this kind can only show absolute data, not figures presented as a ratio, for instance divided by population. This is because the statistics have to be additive so that the total area is made up of the sum of the smaller areas. An inset map is provided to illustrate the land area of each region but if you want to see the population of each region have a look at Figures 6 and 7 below which both use a base map drawn in proportion to population.

The headline tables detailing the work of National portfolio organisations and Major partner museums in 2014/2015 are available for anyone to interrogate (see http://www. artscouncil.org.uk/what-we-do/research-and-data/npo-and-mpm-annualsubmissions/ current-annual-submission/). They show that for the 16 major organisations and museums that are mainly located in London self-direct school visits fell by $13.3 \%$ between $2012 / 2013$ and $2013 / 2014$ to 293,374 a year. Over the same time period other visits rose by $2.3 \%$ to $12,917,299$ a year, and outreach activities fell by $21.5 \%$ to 223,944 a year. So any argument that the increased concentration of arts 
funding in these few major institution is resulting in more outreach activity and visits from schools would be wrong and given the falls outside London in funding in relative terms, if this is the picture for the 16 major national sites that does not bode well for smaller sites outside of the capital.

There are some far more subtle ways in which the power of London and the South East of England is made evident. Instead of just looking at ACE funding of theatres and opera houses (DCMS, 2012; DCMS \& DfE, 2015), or the multi-billion cost of residential property in a few London boroughs, as compared to entire Northern regions, consider something as apparently benign as electricity generation.
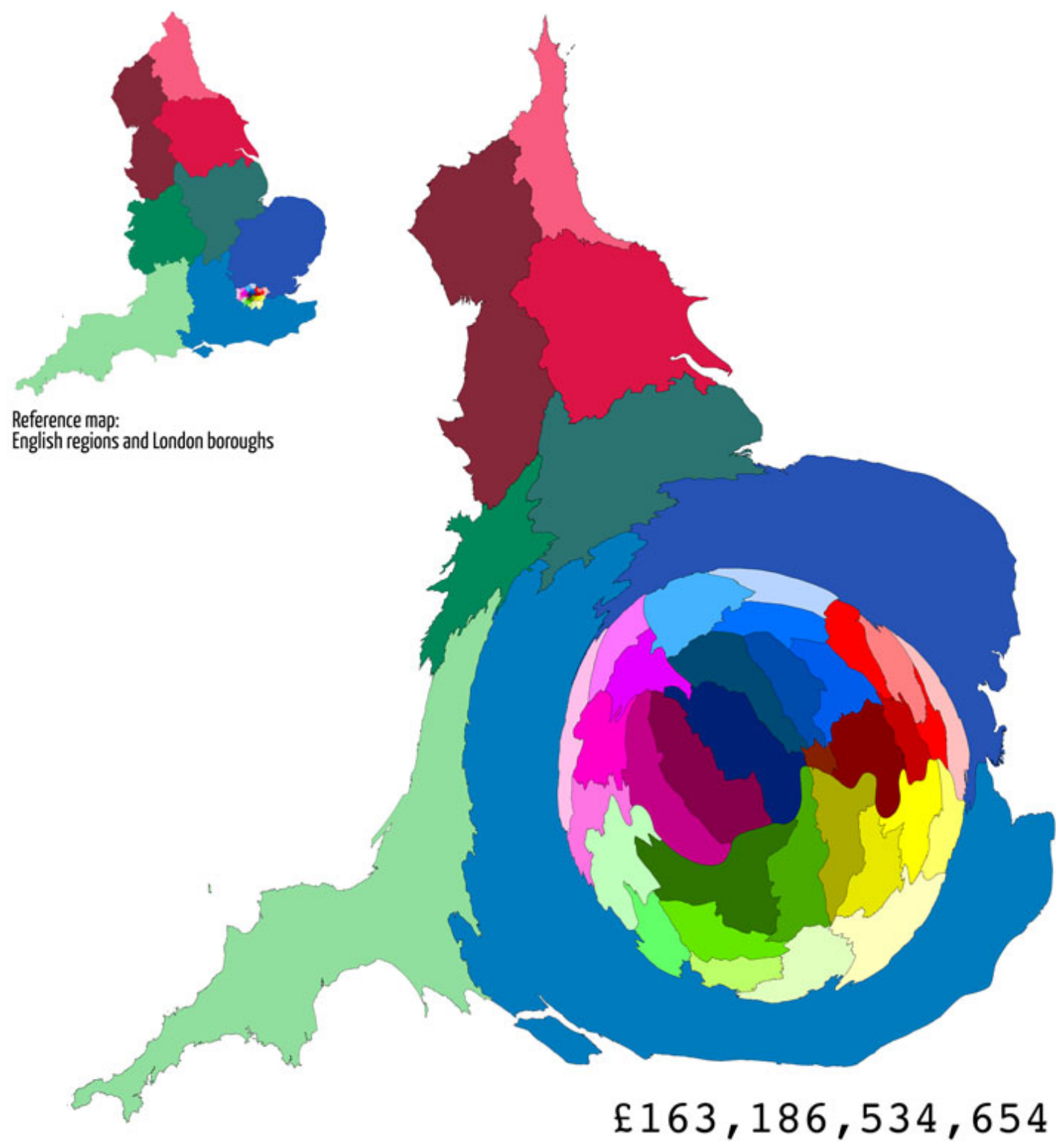

Figure 3. This map of the English regions and boroughs of London illustrates how wealth, in the form of the value of housing, became incredibly concentrated within London by 2014. London housing was, by then worth more than all the housing of the North East of England, North West of England, and Yorkshire and Humberside combined. Since 2014 that concentration of wealth in the capital has risen immensely as the London bubble grows, although figures by borough and region are no longer released so reliably by the land registry as to allow updated maps to be produced as easily as we could last year. 
It makes sense to generate electricity near to where it is consumed because power is lost in long distance transmission lines. Clearly, there are some good reasons for not producing some forms of electricity in some areas. Wind power is often greater on hills. Battersea power station may be worth far more turned into luxury flats and the old turbine hall of Bankside power station is now an art gallery, Tate Modern, grant funded through DCMS, which possibility occasionally receives some ACE funding as well as its controversial sponsorship from British Petroleum (Liberate Tate, 2015). However nuclear power stations need only be located near a source of water for cooling them and, so, could be located nearer London. But they are not.

Figure 4 shows the 20, 30 and $80 \mathrm{~km}$ exclusion rings around nuclear power stations (and a few other similarly dangerous facilities such as Sellafield), first on the normal map and then on the population cartogram of the UK. Clearly avoiding areas of high population is not a priority when situating nuclear power stations. Very large numbers of people living in the North East of England, Yorkshire and Humberside, Greater Manchester, and Greater Cardiff and Bristol would be in the wrong place if the wind were going in the wrong direction at the wrong time. In contrast, hardly anyone who lives in London apart from those on the far South East fringes of the capital lives within $80 \mathrm{~km}$ of a nuclear power station (or similar nuclear facility). Furthermore, this exclusion of the capital is no coincidence. It also occurs in France, for Paris, and in Germany, for both Bonn (the former capital) and Berlin (the current capital).

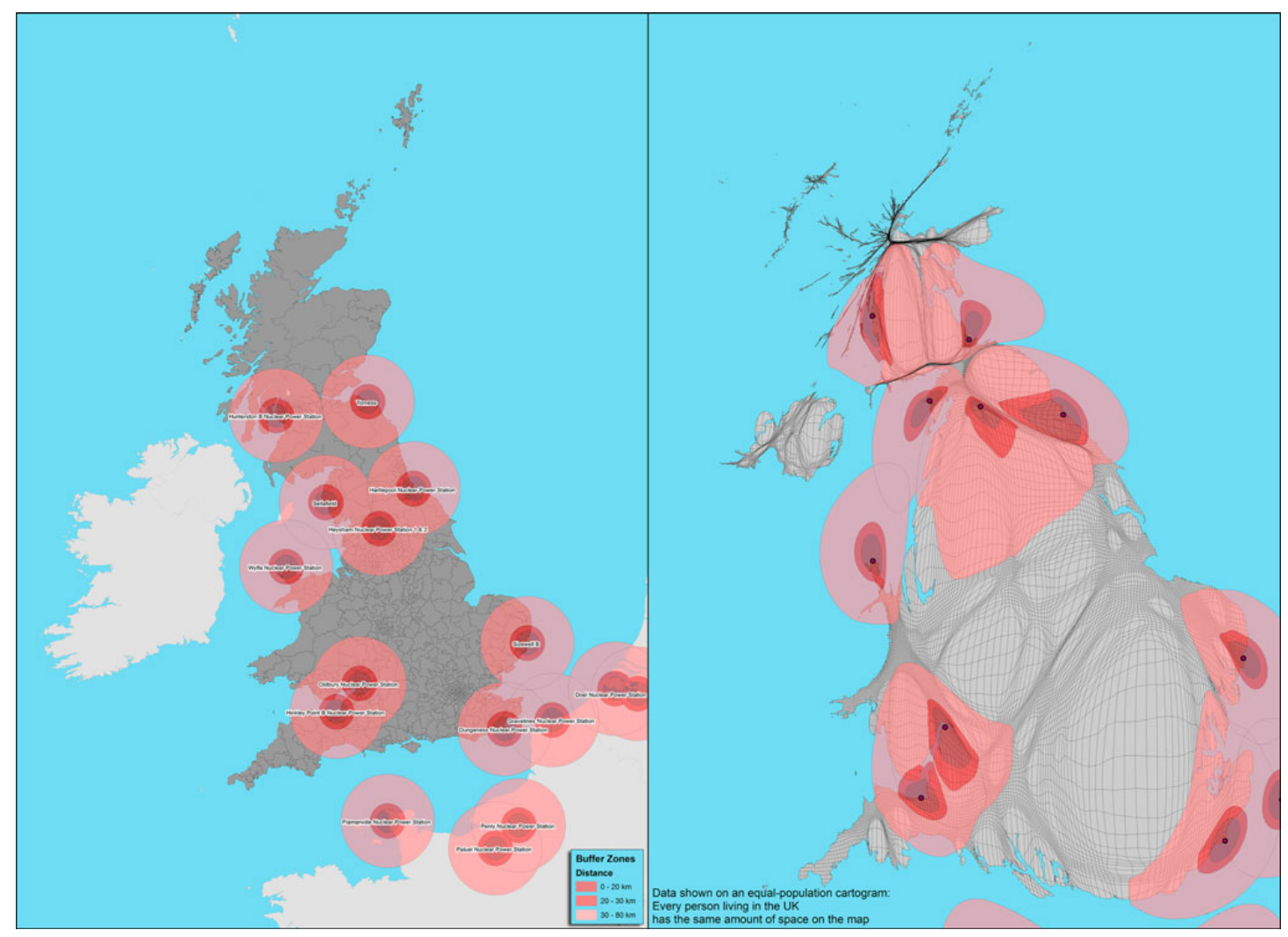

Figure 4. The 20, 30 and $80 \mathrm{~km}$ exclusion rings around nuclear power stations in the UK shown on both an equal land area map and on the population cartogram. Some other facilities are included hear such as Sellafield where spent but highly dangerous fuel is stored. Note how most people living in the North of England live within $80 \mathrm{~km}$ of a nuclear power station that they could presumably visit, should they so wish. In contrast large numbers of people living in London can easily visit many very well-funded arts venues but not a nuclear power station. There are fewer power stations in the English midlands because large sources of water needed to cool the stations are less reliability available there. 
London is a very safe place for people who have an awful lot of money. There is a great deal for them to do, thanks partly to ACE, but also to the concentration of philanthropy (Harvie, 2015). If they buy property, it is worth an enormous amount so even the purchase of relatively small amounts of property in London can allow you to store much of your wealth efficiently. They are unlikely to be affected by disaster, including even a nuclear reactor meltdown and a barrier has been built across the river Thames to protect them from flooding. Billions are spent on new underground train lines and sewers in London from national budgets. London is looked after in a way no other part of the UK is protected.

One effect of the protection of London by the UK government is that the capital has become the favoured location of the world's super-rich, and that affects art funding (Alexander, 2014). Of the richest 1000 people living in the UK in 2014, almost half lived in London. This was the better-off half of the super-rich 1000 who held more than half of the total combined wealth of all 1000. Figure 5 shows where the very richest 16 families of all in the UK live (left map) and how the UK and Ireland appear to look when shaped by the wealth of the super-rich (right map). The English part of the cartogram looks remarkably similar to ACE funding!

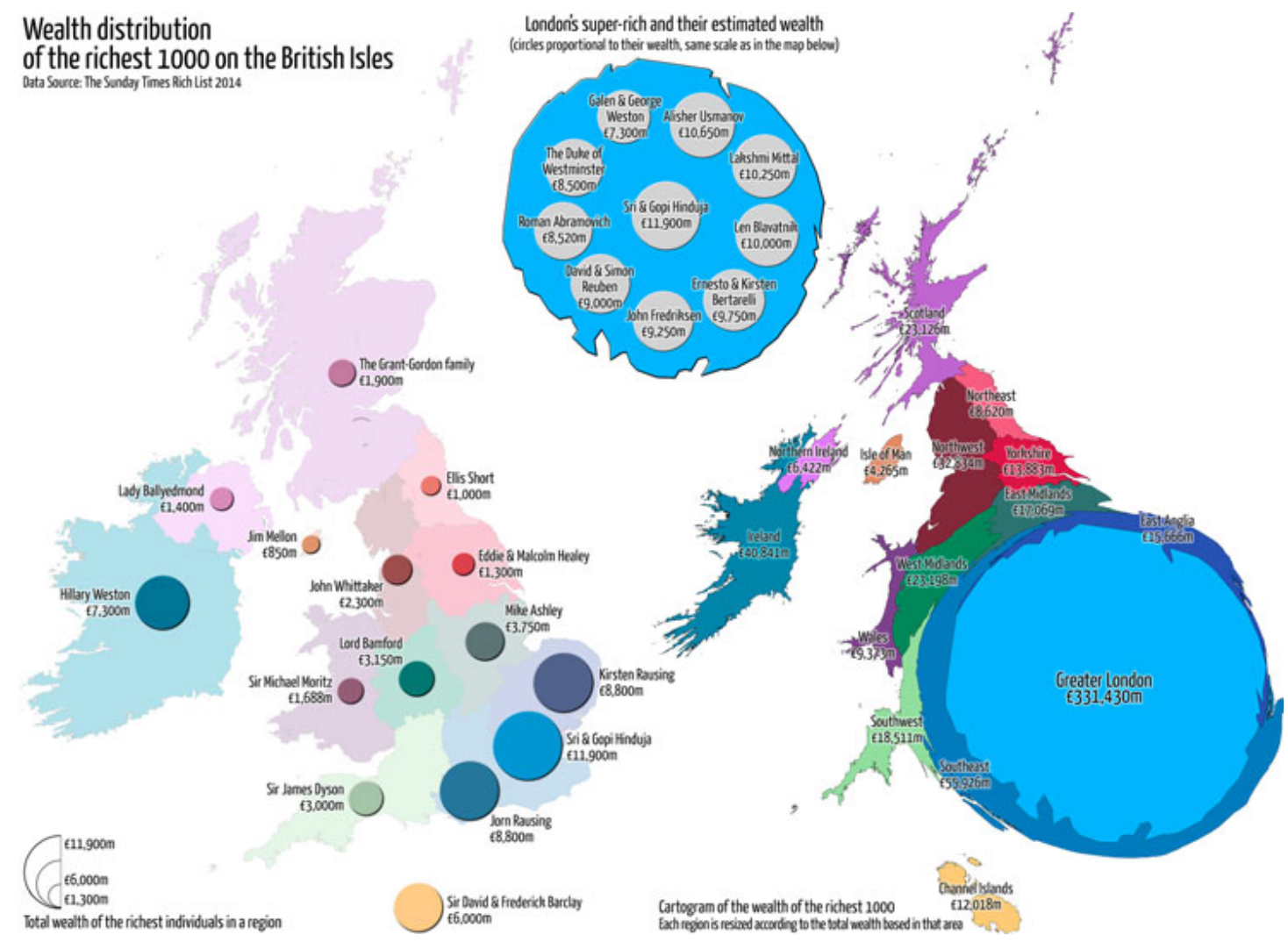

Figure 5. The Sunday Times Magazine produces an annual report on the wealth of the 1000 richest families in the UK and Ireland. In 2014 it included a regional breakdown of the figures that allowed the maps above to be drawn. It is very hard to determine where the main home of very rich people is, because they often own many homes, so we are grateful to the magazine for doing this. In a few cases the same affluent family was listed as having major assets in more than one region and so here they are shown by where their assets are of greatest value. The total area of the cartogram is proportional to the total wealth of these 1000 richest families and the circles drawn for individual families show the total wealth of those particular families who are the richest within each region and the 10 richest in London. 
Of the almost 500 members of London's super-rich, the richest 10 families hold almost a quarter of all the wealth of those 500; the top 13 hold almost a third! Inequality increases the higher you travel up the income and wealth continuums. But, very little is ever said about the great inequities of England, because those at the top wield such power, are such larger donors to political parties, own entire newspaper groups or own the people who run those newspapers.

The English have become culturally attuned to seeing and experiencing a geography of extreme inequality as normal. As a penultimate example of the concentration of cultural capital, wealth and power, consider university funding: The figure below shows government "Quality-related" $(\mathrm{QR})$ research funding per higher education institution divided by the numbers of students taught. This constitutes - if you like the "spare money" that makes things possible in those institutions that are deemed to be better at research. Perhaps, a little unexpectedly, when divided by the student population who expect to be taught, the distribution of QR funding is just as South East- and London-skewed as everything else we have shown in this short paper. There is no special "northern-powerhouse" when it comes to education, just as there is not with housing prices, or with arts funding, and just as there is no small northern enclave of the rich and powerful in the Sunday Times rich list and just as there is no area of the north deemed so special that no nuclear power station (or similar facility) can be built within $80 \mathrm{~km}$ of any large group of people living in the North.

The four large red circles shown in Figure 6 are (from West to East): Oxford, Imperial, UCL and Cambridge. These are the four large universities that receive more than $£ 3000$ a year in QR funding for every student they teach. The funding is not for teaching, but it certainly makes teaching them easier. The three large purple-coloured universities are Bristol, King's College and Queen Mary (London). In each of those, QR funding is awarded at a level of between $£ 2000$ and $£ 3000$ per student. Each institution is drawn as a circle proportional to the number of students studying there by all ages and types. Clearly, as you head North the proportion of universities coloured brighter colours, or even dark blue, falls. To them that have, more is given.

The situation in the UK is unusual for Europe. It is also unusual for an Englishspeaking, affluent country. In the rest of the rich English-speaking world, capital cities tend to be small: Washington DC, Ottawa, Canberra, Wellington and New Delhi. In mainland Europe, the elite are not as elite as in the UK. Top salaries are lower; less wealth held by so few families. You might say that it does not matter that the wealth of the USA is in New York, rather than in Washington DC, but it is also in Los Angles, in San Francisco and in Miami. Only in Russia, where Moscow is so dominant can we find another country where the capital is home to such a large proportion of the population, where no second city is of great significance and where the take of people in that city is, on average so high even though most, on average, are not doing so well in the Capital. Other European capitals such as Paris, Lisbon, Madrid and Athens do dominate their countries but not as much as London by any measure of GDP per capita. Having a high GDP rate does not mean that Londoners are necessarily more productive. A few may well be especially good at securing income they have not really earned through hard work. For example, there are well over 2000 bankers paid over a million Euros a year in salary and bonuses in London. The next highest concentration in Europe is found in Germany where there are 197 such well-paid financiers (Dorling, 2015). 

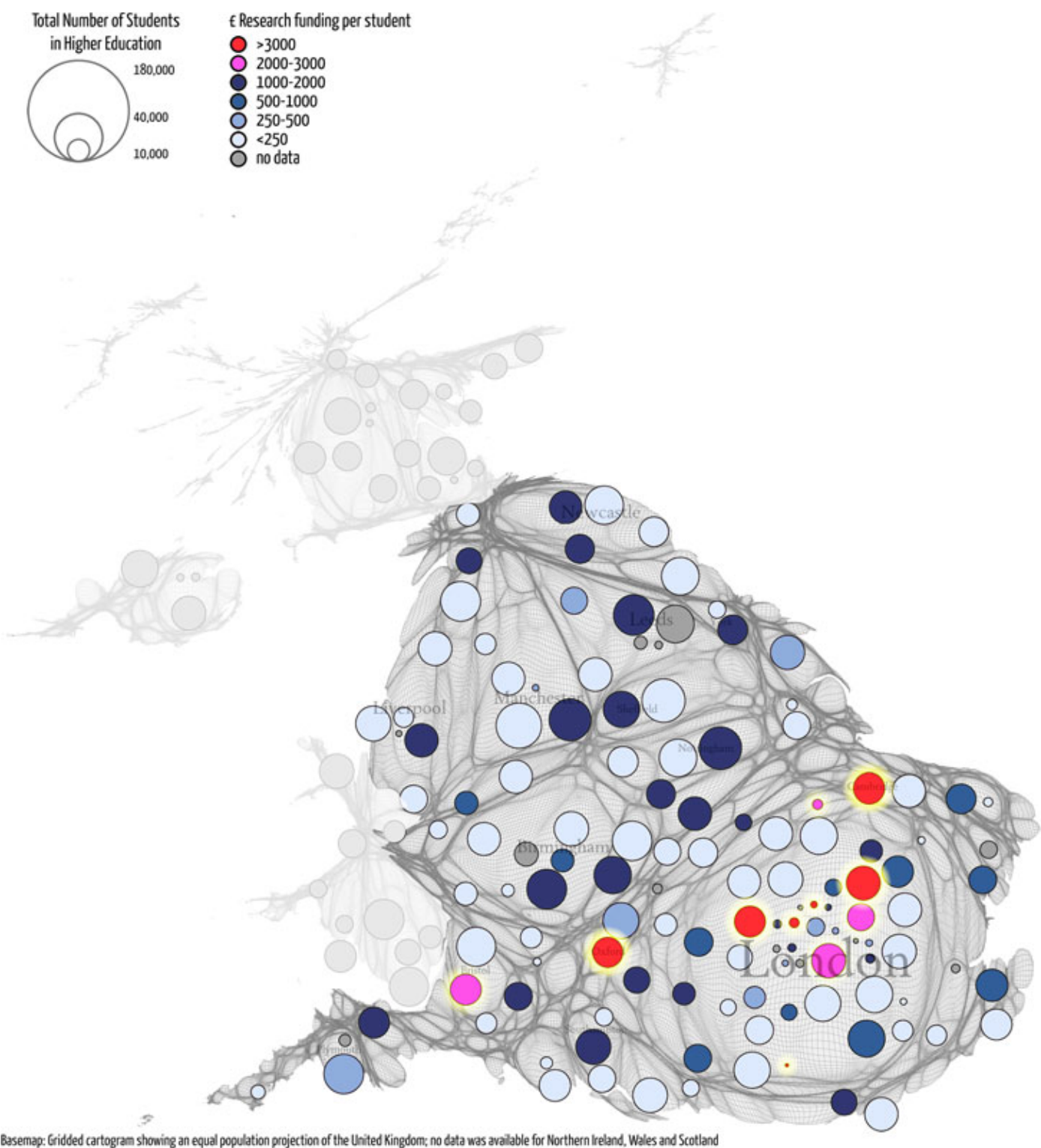

Figure 6. In this map a circle is drawn to represent each university with its size in proportion to the number of students studying there, located where the university main campus is. The circles are then coloured according to the ratio of government research funding awarded per student. The research funding is not for students so this is an innovative and unusual measure. Data were only available for England at the time of drawing this map. In many ways Cambridge and Oxford are London suburbs today so the interesting exception is Bristol, which does not quite fit the mould, although the train from there to London does not take very long at all to travel into the heart of the capital.

Part of the reason why the UK is so unequal when it comes to its elite, wealth and influence is that it has not be invaded, suffered a revolution or a civil war, at least for a very long time. The tanks have not rolled over the fields of England. While US banks, effectively, invaded the City of London in the 1970s and 1980s, that invasion was largely invisible. Britain's ability to lead a resurgence of elitism is largely a consequence of the influx of new money in the last few decades: money from Russia, from Saudi Arabia, from Greece, from the super-rich from all over the planet. In particular the UK has become a safe haven from wealth of dubious origin. 
Money from abroad disproportionately arrived in London, which allowed for investors' anonymity. And demand for yet more art installations, theatres, shows, galleries, events, happenings and beings grew and grew. London auction houses saw the prices escalate ever higher for fine art, modern art, any art and the city became the place to be and play. London property prices boomed, London energy needs escalated, the London super-rich descended with ever-greater coffers. New money squeezed out old and the universities to gain most were all in the South: Bristol, Kings, UCL, Queen Mary rose up among old stalwarts such as Imperial and the country cousins of Oxford and Cambridge - both, in effect, now suburban London exclaves.

Just three decades ago, it was possible to read convincing accounts of how all the old divisions were falling apart as the capital was imploding economically and demographically (Wright, 2009). A lot can happen in a few decades and a great deal could happen in a just a few years from now.

It is not just the super-rich that matter. When it comes to visiting galleries and museums and having the time and money (for travel) to do so other economic inequalities in the UK matter. The best-off $10 \%$ of the population of the UK enjoy an annual income that is over 10 times that enjoyed by the poorest tenth (Stotesbury \& Dorling, 2015). In France that ratio is 7:1, in Germany 6.5:1, in Sweden 6:1 and in Denmark 5:1. The wealth of the best-off 10\% living within London is over 100 times greater than that of the poorest 10\% (Dorling, 2015). People in the UK live parallel lives and this is so accepted as normal that it is frequently not even recognised as a problem.

There is nothing immutable about the distribution of arts funding. It has not always been as disproportionate as this, and it need not be like this in future. However, the UK has been every unequal for several decades now, despite in the 1960s being the second most equitable large nation after Sweden. In the 1960s we produced the Beatles and the Rolling Stones. Greater equality does not stifle creativity. Greater equality also helps you see others as more like you.

In Japan, after one nuclear disaster, the Japanese turned all the reactors off everywhere and did all that was possible to aid those worse effected. Contrast that with the treatment of the citizens of New Orleans after Hurricane Katrina struck and then think how the British might behave. Would we be more like the Americans or more like the Japanese. House prices can crash, but the super-rich can always find new homes. Universities, deemed to be so great at one moment in time, can have the curtain pulled back and appear far less excellent at another point. London's apparent cultural dominance may at some point attract some derision.

There is no need for England to remain a cultural desert and for London to continue to be the magic money tree, the well of bounty and the place of excess. Figure 7 shows how areas that vote most often for the dominant political party encircle London, and how a serpentine shaped sliver of such voters cuts into the heart of the capital. Compare this map of voting to that Graeme Evans' paper in this issue of Cultural Trends (2016). As Britain approaches the end of the second decade of the twenty-first century in many ways it resembles a country at such dis-ease with itself that it is difficult to imagine these divides being sustained and widened for much longer. 


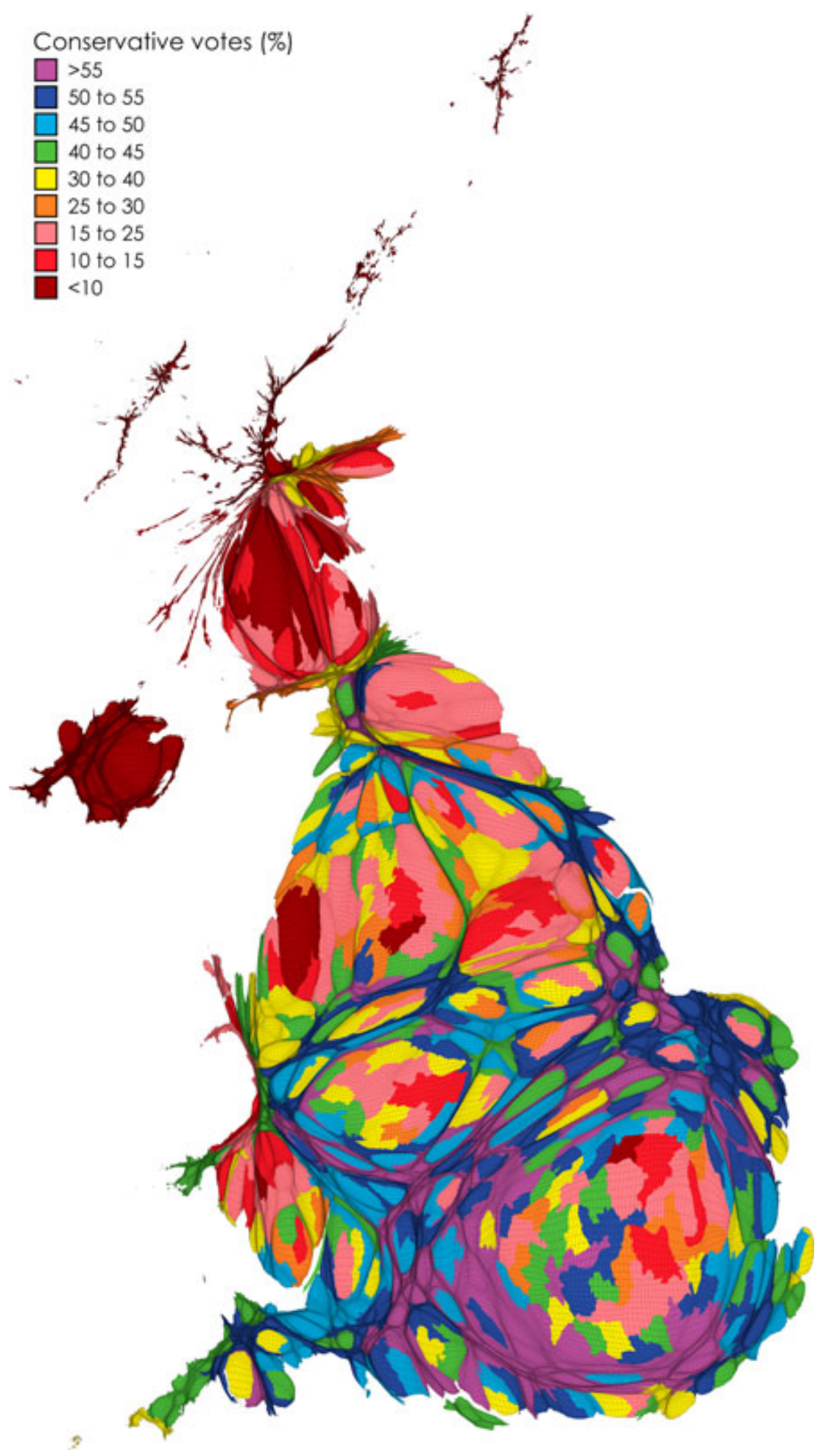

Figure 7. In this figure each parliamentary constituency of the UK is drawn in proportion to the population living there and coloured according to the share of the vote won by the Conservative party in the May 2015 general election. Those who did not vote are ignored. In a few areas, coloured blue or purple, a narrow majority of the voters did vote for the party that gained power. Everywhere else only a minority of voters, and an even smaller proportion of the registered electorate, voted for the party that actually secured the most seats in parliament and a majority of 12 MPs. This was possible because there were many opposition parties in England: Labour, Green, Liberal, and UKIP; and because of the archaic "Westminster" first-past-the-post voting system, itself another example of London cultural dominance. 
Currently, London is the most expensive city in the world to live in it. It houses some of the greatest collections of art, in one of the safest environments on the planet surround by some of the greatest seats of learning, many of which it contains. But all this is only true if you believe those who construct the statistics that say which university is best, just as if you believe those who tell you where the arts money must flow to or from which areas power must be drawn and lottery tickets purchased (Naidoo, 2016). You have to believe that property in London is really worth this much and not look at its quality to believe this is sustainable. You have to believe that the art that rich chose to buy is the very best art, and not just that which they think might increase most in value if people like them continue to buy it, and be rich enough to do so.

Art, money and learning tend to follow each other around the globe over time (A\&B, 2013). From Renaissance Florence, to Dutch Masters, to French impressionism to American modern art - geography, culture and cash have always been entwined, and always move with the times. There is always a geography to culture and cultural geography is currently the vogue subject of the academic discipline of geography. And fashion always changes. The most popular place in the world for the rich to one at least one of their homes in does not remain the most fashionable place for ever. That is the point of fashion - to change.

Look at the UK a little differently, stretch the map to show the people, colour the areas to highlight the money, and pinpoint what it is that often matters most - and it is possible to make visible what is usually invisible. Follow the money and draw the map. Then step back and see what there is to be seen. You can see the patterns without the maps, but only vaguely, not in focus. Individual researchers comment that "Local arts organisations struggle to get the corporate support which flows to the major charities" (Pharoah, 2011, p. 74). In the light of a much bigger picture so much that we complain about is just part of what is normal in a highly divided society.

There is much more to culture in the UK than London and an English desert, but when it comes to culture that is backed up by cash and the culture of the elite, of their homes, their art collections what they (and the rest of the best-off 10\%) visit and what they fear, all our geographical pictures are becoming sharper and the divides starker (Bull, 2015). It is normally when they become most stark that we start to again most notice the differences. That is when the jazz age ends, when the opulence is seen to have gone too far, when the tulip buying frenzy ends, and when someone - finally asks why the emperor is wearing no clothes. Just how good is all this art that you do not share?

Disclosure statement No potential conflict of interest was reported by the authors.

\section{References}

A\&B (2013) The latest private investment in culture survey 2011/12. Retrieved from http:// artsandbusiness.bitc.org.uk/research

Alexander, V. D. (2014). Art and the twenty-first century gift: Corporate philanthropy and government funding in the cultural sector. Anthropological Forum, 24(4), 364-380. 
Brook, O. (2016). Spatial equity and cultural participation: How access influences attendance at museums and galleries in London. Cultural Trends, 25, 1. AQ2

Bull, D. (2015). Culture in a cold climate. Cultural Trends, 24(1), 46-50. 9

Dorling, D. (2015). Inequality and the 1\%. (2nd ed.). London: Verso.

DCMS (2012). Digital giving in the arts - democratising philanthropy. Retrieved from https://www.gov. uk/government/publications/digital-giving-in-the-arts-democratisingphilanthropy

DCMS \& DfE (2015). Policy paper: 2010-15 Government policy: Arts \& culture. Retrieved from https:// www.gov.uk/government/publications/2010-to-2015-government-policy-arts-andculture/2010- to-2015-government-policy-arts-and-culture

Evans, G. (2016). Participation and provision in arts \& culture - bridging the divide. Cultural Trends, 95, 1. AQ3

Gavier, J. (1958). Paris et le désert français. Paris: Editions Flammarion. ๆ Harvie, J. (2015). Funding, philanthropy, structural inequality and decline in England's theatre ecology. Cultural Trends, 24(1), 56-61.

Hutchison, R. (1982). A hard fact to swallow: The division of arts council expenditure between London and the English regions (A working paper by Robert Hutchison for the Policy Studies Institute).

Liberate Tate (2015). £224,000 of 'BP Money' Thrown from top of Tate Britain into its Oil Company Sponsored Galleries', January 31. Retrieved from https://liberatetate.wordpress.com/2015/01/31/224000pounds-bp-money-thrown-into-tate-oilcompany-sponsored-galleries/

Mermeri, T. (2010). Arts philanthropy: The facts, trends and potential. Retrieved from http://www. aandbscotland.org.uk/documents/2012-06-12-10-42-58-31-Arts-philanthropyfacts-trends.pdf

Naidoo, R. (2016). The only game in town - the coalition, culture and neo-liberalism, cultural trends. Cultural Trends, 24(1), 62-65.

Pharoah, C. (2011). Private giving and philanthropy - their place in the big society. People, Place \& Policy Online, 5/2, 65-75.

Phillips, P. S. (2012). Philanthropy beyond London a report commissioned by the secretary of state for culture, media and sport. Retrieved from https://www.gov.uk/government/uploads/system/ uploads/attachment_data/file/78577/philanthropy_in_the_regions.pdf

Stark, P., Gordon, C., \& Powell, D. (2013). Rebalancing our cultural capital: A contribution to the debate on national policy for the arts and culture in England. Retrieved from http://www.gpsculture.co.uk/ downloads/rocc/Rebalancing_FINAL_10mb.pdf

Stotesbury, N., \& Dorling, D. (2015). Understanding income inequality and its implications: Why better statistics are needed, statistics views, October 21. Retrieved from http://www.statisticsviews.com/ details/feature/8493411/Understanding-Income-Inequality-andits-Implications-Why-Better- Statistics-Are-N.html

Wright, P. (2009). A journey through ruins: The last days of London. Oxford: OUP. 